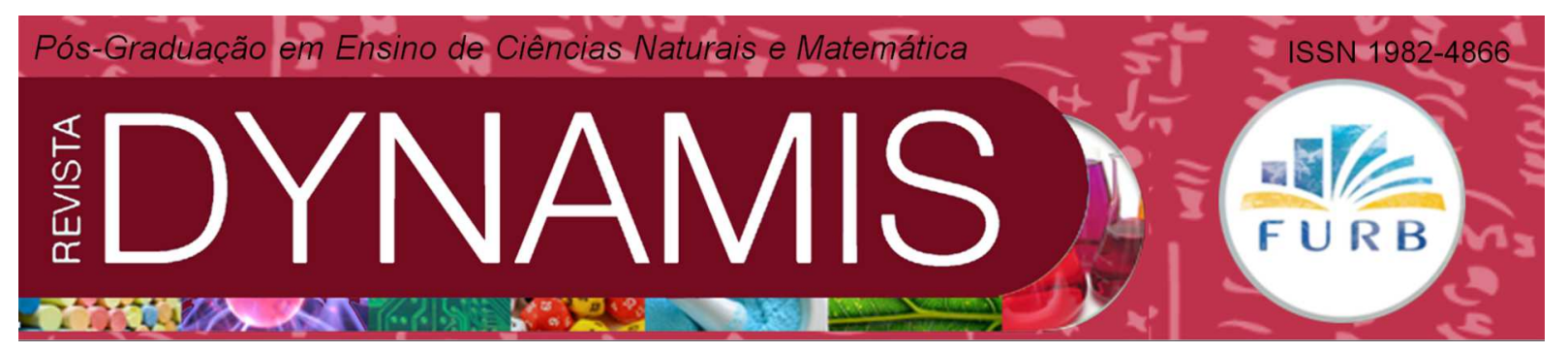

\title{
JOGOS PARA O ESTUDO DA MATEMÁTICA NO ENSINO FUNDAMENTAL
}

Games for the study of Mathematics in Elementary Education

Claudimara da Silva Pfiffer

Programa de Pós-Graduação em Ensino de Ciências Naturais e Matemática - PPGECIM/FURB Universidade Regional de Blumenau

claudimara.mat@gmail.com

\section{Tânia Baier}

Programa de Pós-Graduação em Ensino de Ciências Naturais e Matemática - PPGECIM/FURB Universidade Regional de Blumenau baier@furb.br 


\title{
Resumo
}

Neste artigo, são apresentadas as possibilidades pedagógicas dos jogos, um recurso didático para o estudo da matemática, no ensino fundamental, sendo destacado o papel do professor como organizador e observador das ações realizadas pelas crianças durante as partidas. Trazendo o lúdico para a sala de aula, os jogos promovem: a sociabilidade e a interação entre estudantes e professor, a oportunidade de tomada de decisões e o desenvolvimento da autonomia. Jogos contribuem para que cada estudante conheça seus limites, possibilitam o exercício de concentração e do controle da ansiedade e podem estimular a prática do cálculo mental. Erros cometidos durante a realização de jogos são mais facilmente superados do que aqueles escritos em avaliações. Vencer um jogo demanda seguimento de regras e respeito aos colegas: atitudes exigidas no convívio social. Cabe ao professor o papel de planejar a realização de jogos, observar atentamente a realização das jogadas, identificar crianças que demandam auxílio e atuar como juiz em desavenças que eventualmente ocorram.

Palavras-chave: Jogos. Ensino Fundamental. Matemática.

\begin{abstract}
In this article, games are presented as a teaching resource for the study of mathematics in elementary school. The text discusses the pedagogical possibilities of using games and it is focused on the role of the teacher as facilitator and observer of the actions performed by children during matches. Bringing fun to the classroom, those games promote sociability and interaction between students and the teacher, and the opportunity for decision-making and the development of autonomy. Games also help the students to get to know their limits, enable the exercise of concentration and anxiety control and can stimulate the practice of mental calculation. Mistakes made during the course of games are more easily overcome than those written in evaluations. Winning a match demands following rules and respect for colleagues, which are attitudes required in social life. The teacher has the role of planning the games, watching carefully the students as they perform the moves, identify children who require assistance and act as judge in disputes that may occur.
\end{abstract}

Keywords: Games. Elementary Education. Mathematics. 


\title{
1 INTRODUÇÃO
}

Os Parâmetros Curriculares Nacionais para a Matemática do Ensino Fundamental (BRASIL, 1998) recomendam a utilização de jogos no ensino de matemática, porém, não orientam o professor em relação ao modo como pode ser encaminhado o trabalho pedagógico antes ou após o jogo, quais contribuições o jogo pode trazer para um ambiente escolar e quais habilidades pode desenvolver nos alunos.

Ao decidir pela utilização de jogos em suas aulas, é importante que o professor escolha jogos com regras que promovam interação entre os estudantes e que envolvam desafios matemáticos. Para Starepravo (2009, p. 21), é fundamental que o jogo "[...] realmente constitua desafios." Alves (2001) considera que a realização de jogos didáticos possibilita a ocorrência de situações desafiadoras, desenvolve a linguagem e a interação social e, enquanto o jogo é realizado, o estudante precisa pensar, estruturar-se cognitivamente, elaborar estratégias, explorar seu conhecimento em relação ao conteúdo, desenvolvendo ações para alcançar seu objetivo que é ganhar o jogo.

De modo similar, Grando (1995, p. 77) explica:

\begin{abstract}
A ação no jogo, tanto quanto no problema, envolve um objetivo único que é vencer o jogo ou resolver o problema e, em ambos os casos, o indivíduo se sente desafiado e motivado a cumprir tal objetivo. Atingir o objetivo implica em dominar, em conhecer, em compreender todos os aspectos envolvidos na ação e, portanto, produzir conhecimento.
\end{abstract}

A seguir, são apresentadas algumas possibilidades pedagógicas destacadas por pesquisadores que investigaram o uso de jogos objetivando o ensino da matemática.

\section{O USO DE JOGOS: POSSIBILIDADES PEDAGÓGICAS}

É comum crianças e adolescentes se sentirem desorientados, por desconhecerem seus limites e não saberem o que podem e o que não podem fazer em determinados momentos. Neste aspecto, Lopes (1999, p.40) considera que o jogo com regras auxilia as crianças a "[...] aprender conceitos básicos da vida, sendo obrigadas a se enquadrar em determinadas regras para realizar algo, aprendendo a respeitar para ser respeitado", ou seja, desenvolvem a confiança básica em si e no colega, criando hábitos de obediência e respeito.

O estudante, ao estar diante de um jogo, aprende a desenvolver o controle de suas ações e a autodisciplina é também um fator determinante. Macedo, Petty e Passos (2005, p.31) indicam que o estudante "[...] precisa desenvolver sistemas de controles internos, o que implica aprender a esperar a vez, observar o que o outro está fazendo e obedecer às regras". Esse processo, que envolve o controle de suas ações, tende a melhorar a cada nova partida ou a cada novo jogo e o estudante o aceita como recurso a seu favor, pois percebe que esse controle pode auxiliá-lo a ganhar o jogo.

Durante a realização de um jogo, o estudante avalia o que errou e o que precisa ser trabalhado e a consequência será o aprimoramento dos seus conhecimentos. Para que isso aconteça de forma natural, é necessário que o professor passe orientações sobre a possibilidade de der- 
rota e que há sempre a oportunidade de outra partida. Os estudantes socializam suas dúvidas com o objetivo de buscar mais conhecimento:

[...] as crianças (adversários) se ajudam durante as jogadas, esclarecendo regras e, até mesmo, apontando melhores jogadas (estratégias). A competição fica minimizada. O objetivo torna-se a socialização do conhecimento do jogo. Além disso, nesse processo de socialização no jogo, a criança ouve o colega e discute, identificando diferentes perspectivas e se justificando. Ao se justificar, argumenta e reflete sobre os seus próprios procedimentos. (GRANDO, 2000, p. 29)

Além disso, o estudante observa as jogadas realizadas e constata que precisa trabalhar nas suas dificuldades quando percebe que seu oponente já desenvolveu estratégias que possibilitam vencer o jogo. Desse modo, conhece seus limites e procura elaborar estratégias para superá-los.

A realização de jogos possibilita o exercício de controle da ansiedade, encontrada em muitas pessoas, provocada pelas pressões diárias, pela falta de concentração, de autoestima e de relacionamentos saudáveis. Percebe-se que, numa sala de aula com estudantes ansiosos, inquietos, falantes e que se movimentam o tempo todo, há um prejuízo no trabalho do professor e no aprendizado de alguns que necessitam de mais concentração. Para Lopes (1999, p. 39), o jogo cria "“...] novos hábitos salutares [...] incorporados à vida da criança, e pode recriar sua visão de mundo e sua atuação nele", gerando controle de ansiedade, proporcionando uma sensação de capacidade e de realização.

O desenvolvimento da autonomia é um aspecto fundamental para que os estudantes realizem as atividades que demandam tomadas de decisões, ou seja, sozinhos. Segundo Lopes (1999, p. 41), "[...] alguns jogos têm como objetivo o desenvolvimento da autonomia da criança: poder arriscar-se, ter de fazer a sua parte sozinha e ser responsável por suas escolhas", possibilitando o erro ou o acerto nas jogadas, revelando o que é capaz e que pode ser responsável por muitos atos e escolhas.

Smole, Diniz e Milani (2007, p.10) constatam que “[...] o aspecto lúdico faz do jogo um contexto natural para o surgimento de situações-problema cuja superação exige do jogador alguma aprendizagem e certo esforço para busca de solução." Desse modo os jogos auxiliam o estudante a superar seus próprios obstáculos, controlando seus pontos e os do seu adversário.

O professor deve assumir o papel de mediador e desenvolver a autonomia dos estudantes no aprendizado, incentivando-os a pensar e a tomar decisões sozinhos. Kamii e Declark (1986, p. 169) constatam: "Folhas de exercícios apresentam problemas pouco originais, bem organizados e numa forma pura. O professor explica para os alunos quais são os problemas e se acha responsável por ensinar a eles como resolvê-los". Segundo essas autoras, o jogo auxilia os estudantes a pensar mais detalhadamente sobre suas dúvidas e a desenvolver argumentos próprios de sua realidade.

Durante a realização de um jogo, pode ocorrer que estudantes encontram dificuldades, mas podem facilmente verificar o resultado encontrado. No estudo de Macedo (1997), o jogo auxilia o professor a reconhecer os erros cometidos e as estratégias utilizadas pelos estudantes no decorrer da partida. Não acontecendo uma jogada favorável, o estudante revê a estratégia utilizada, percebe o que deve ser diferente ou constata apenas a falta de atenção. Com a repetição do jogo, o estudante corrige seus erros e aprende a observar com mais atenção os seus procedimentos e os do seu adversário. De acordo com Macedo (1994, p. 39), “[...] os jogos 
são úteis para evidenciar um erro, torná-lo observável", o estudante sente-se mais questionador e observa com mais detalhe algum conceito ou questão não percebida anteriormente.

O jogo, segundo Bôas (2007), possibilita que os erros possam ser observados gerando dados para análise e reflexão e contribui para que o estudante enfrente um erro de uma maneira mais curiosa e ativa. Kishimoto (1994, p. 21) aponta o benefício gerado pelo uso de jogos no caso de ocorrência de erros:

O jogo favorece o aprendizado pelo erro e estimula a exploração e a resolução de problemas. O jogo, por ser livre de pressões e avaliações, cria um clima adequado para a investigação e a busca de soluções. O benefício do jogo está nessa possibilidade de estimular a exploração em busca de respostas, em não se constranger quando se erra.

O erro auxilia o professor a perceber quais conceitos foram compreendidos, quais as relações e as observações percebidas pelo estudante e constatar as hipóteses utilizadas durante o jogo. Para Grando (2000, p. 41), "[...] é durante esse processo que são garantidas algumas estruturas matemáticas, desejadas numa situação de intervenção com jogos".

Durante um jogo, mesmo que o estudante perde a partida, reavalia o que precisa ser melhorado, para ganhar a próxima. Grando (2000, p. 28) afirma: “[...] é na ação do jogo que o sujeito, mesmo que venha a ser derrotado, pode conhecer-se, estabelecer o limite de sua competência enquanto jogador e reavaliar o que precisa ser trabalhado, desenvolvendo suas potencialidades". Assim, o jogo possibilita que estudante reflita, analise e compreenda conceitos matemáticos que às vezes não são totalmente entendidos quando são ensinados no quadro pelo professor ou através de exercícios no caderno.

Quando o estudante perde ou ganha uma partida, o professor tem a possibilidade de perceber se entendeu as regras e compreendeu o conteúdo. Teixeira (2008, p. 66) considera que "[...] a análise do erro e do acerto pelo aluno se dá de maneira dinâmica e efetiva, proporcionando a reflexão e a re(criação) de conceitos matemáticos que estão sendo discutidos", além de analisar e compreender o desenvolvimento do raciocínio do estudante. A autora ainda defende que o objetivo do professor no trabalho com jogos é valorizar o papel pedagógico do jogo, desenvolvendo a exploração ou a aplicação de conceitos matemáticos.

Um desafio em sala de aula é promover atividades que despertem a concentração dos estudantes e que exijam um grau maior de atenção. Para que isso ocorra é importante trabalhar com atividades minuciosas, como a visualização de objetos diferentes dentro de um conjunto, tal prática pode auxiliar no desenvolvimento da atenção. (LOPES, 1990).

Segundo Kimura (2005, p. 135), o jogo de regra é muito importante, pois possibilita que o estudante seja "[...] capaz de fazer antecipações, prognosticar, coordenar situações, criar estratégias, ser habilidoso, ter boa memória, estar atento e concentrado, saber abstrair, relacionar jogada durante todo o jogo". Para a autora, a repetição exigida no jogo apresenta um aspecto interessante: ao jogar o estudante precisa analisar diferentes pontos de vista para atingir o melhor resultado, ou seja, as descobertas percebidas são constantemente compartilhadas com seus colegas e, quando são discutidas, o estudante aprende a defender suas ideias.

Todos os jogos que exigem planejamento e estratégia para jogar estimulam o estudante ao raciocínio lógico. Lopes $(1999$, p. 45) pontua que os estudantes "[...] preferem não pensar para solucionar problemas e vêm com as famosas perguntas: Que conta é? É de mais ou de 
menos?". Nesses casos, os estudantes preferem perguntar ao professor a resposta ou dicas para a solução, em vez de pensar. É importante que o professor trabalhe sempre com o objetivo de desenvolver o raciocínio lógico de seus estudantes, permitindo que eles próprios façam as reflexões necessárias e estimule a usar o cálculo mental para aprenderem a solucionar problemas.

Para estimular o raciocínio, é importante que o estudante realize cálculo mental. Em situações de multiplicação, quando se questiona como se calcula mentalmente, normalmente os estudantes calculam usando o algoritmo convencional. O cálculo mental deve ser um cálculo pensado, não mecânico, estabelecendo a compreensão das relações envolvidas. (STAREPRAVO, 2009).

O jogo implica em tomar decisões e explorar a noção matemática. Grando (2000, p. 57) constata que "trabalhar com o conceito matemático no jogo significa compreender tais ações e reestruturá-las em um nível mental", estabelecendo relações e estratégias, interpretando e observando o seu adversário. Raupp (2009, p.29) considera:

\footnotetext{
O jogo, principalmente aos pares, tem seu valor pedagógico ao propiciar uma ampla interação entre os participantes, conduzindo a utilizar ou formar novos conceitos, que proporcionem ao educando desenvolver o raciocínio e outras habilidades, além das que possui, e realmente desafiando a inteligência.
}

Quando joga, o estudante movimenta as peças diversas vezes, na tentativa de acerto ou erro. É importante que o professor solicite o uso da linguagem oral justificando a estratégia usada na movimentação das peças, de modo que o estudante possa expressar o seu pensamento e seu conhecimento do jogo. Segundo Lacanallo (2011, p. 107), o jogo deve "[...] promover condições que levem o sujeito a pensar, num primeiro momento, em voz alta e depois internamente, sobre suas jogadas", e, para que isso ocorra é importante um determinado tempo para que a linguagem mental se organize e se expresse externamente.

Nos jogos, as regras são aceitas de maneira natural, mas são cobradas pelo grupo quando se constata a sua violação. Para Friedmann (1996, p.35), “[...] a regra é considerada como uma lei imposta pelo consentimento mútuo, cujo respeito é obrigatório, permitindo-se transformá-la desde que haja consenso geral", nesse caso, a regra é que organiza o jogo e torna o estudante mais autônomo em suas decisões. Kimura (2005, p. 22) alerta que, durante a realização de um jogo, há "[...] um conjunto de leis imposto pelo grupo, sendo seu descumprimento normalmente penalizado, e há uma forte competição entre os indivíduos".

Ao ser iniciada uma atividade com jogos, a leitura das regras pode ser realizada pelo professor e ainda, se houver necessidade, pode ocorrer a realização de uma partida para auxiliar na compreensão das regras. Smole, Diniz e Milani (2007, p.16) sugerem que "[...] a leitura pode ser coletiva, a partir de uma exposição das regras por um meio audiovisual", facilitando a leitura em grupo. Raupp (2009, p. 27) recomenda: “[...] a leitura em voz alta por uma colega ou pelo professor, que dá a devida entonação ao texto", e, nesse caso, o estudante consegue se organizar mentalmente para compreender as regras e se houver dúvidas pode promover a discussão.

O jogo auxilia no desenvolvimento social, moral, cognitivo, bem como político e emocional. O cumprimento das regras de um jogo expressa respeito pelo adversário e constitui a condição básica de sua existência. Cabe ao professor orientar os estudantes para que as cum- 
pram na íntegra, exercendo seu papel de orientador e juiz em sala de aula. (FRIEDMANN; 1996).

Uma das maneiras de apresentar as regras de um jogo é realizar partidas como modelo: o professor joga algumas partidas só com um estudante e os demais ficam assistindo, promovendo um tempo para conhecer as regras e discutir as dúvidas. Segundo Grando (2000, p. 44):

Este é o momento do jogo pelo jogo, do jogo espontâneo simplesmente, em que se possibilita ao aluno jogar para garantir a compreensão das regras. Neste momento, são exploradas as noções matemáticas contidas no jogo. $\mathrm{O}$ importante é a internalização das regras, pelos alunos. Joga-se para garantir que as regras tenham sido compreendidas e que vão sendo cumpridas.

Para Teixeira (2008, p. 63), é na atividade que “[...] o aluno pode compreender que, em seu futuro profissional, a interação e troca de idéias serão relevantes para poder bem desempenhar seu papel na sociedade”. Essa troca de informações, de acordo com o cumprimento das regras, expõe o que cada adversário pensa e que estratégias são usadas durante o jogo.

Pelo seu aspecto lúdico, o jogo cria um ambiente de maior interação entre os estudantes, motivados pela possibilidade de vencer ou de querer jogar de novo, e ainda controlar os seus resultados e de seus colegas. Segundo Smole, Diniz e Milani (2007, p.10), “[...] a dimensão lúdica envolve desafio, surpresa, possibilidade de fazer de novo, de querer superar seus obstáculos iniciais e o incômodo por não controlar seus resultados".

O jogo também tem o propósito de cooperação, considerando os pontos de vista de cada jogador, sendo que no processo de interação são organizados novos significados, contribuindo para novas aprendizagens. Alves (2001, p. 27-28) destaca que o professor, ao aplicar um jogo, "[...] além dos aspectos cognitivos relevantes para a sua aplicação, não deve ignorar ou menosprezar o aspecto afetivo desencadeado". Considerando a análise de Raupp (2009, p. 29), os jogos "[...] estimulam a ampliação de significados, que podem permitir avançar no conhecimento, e assim, despertar processos internos que promoverão o desenvolvimento", o que indica oportunizar diferentes possibilidades aos estudantes de interagirem e consequentemente de aprenderem juntos.

Enquanto se organizam para jogar, baixar cartas ou lançar dados, os estudantes se observam mais, havendo maior interação entre eles. Normalmente essa observação gera um maior entusiasmo e discussão entre eles, e, muitas vezes, a discussão é gerada em torno de conceitos matemáticos. Nesse caso, sem perceber, os jogadores discutem conteúdos muitas vezes ditos "difíceis" por eles, como é o caso da álgebra. O professor esclarece as dúvidas na medida em que vão surgindo, de modo que, enquanto movimentam as peças do jogo, passam a agir de forma mais coerente. Para Teixeira (2008, p.14), “[...] o jogo educativo é a intenção explícita de provocar aprendizagem", além de promover mais autoconfiança, incentivando-os na correção de suas ações.

Ao manusear peças de um jogo os estudantes as relacionam com um brinquedo, mas, o que determina a sua diferença é o cumprimento de regras cobradas pelos jogadores, motivando-os a jogar. $\mathrm{Na}$ análise de Grando (2000, p.28), “[...] a socialização propiciada por tal atividade não pode ser negligenciada, na medida em que a criação e o cumprimento de regras envolve o se relacionar com o outro que pensa, age e cria estratégias diferenciadas". Mesmo em uma situação de derrota, cada jogador analisa seus erros e avalia o que precisa ser trabalhado. 
Supostamente os estudantes esperam do professor que as atividades trabalhadas em sala gerem um aprendizado e é surpreendente como eles aprendem brincando e interagindo. Segundo Rizzo (1996, p. 40): "O interesse despertado por qualquer atividade lúdica produz como resposta o empenho das forças, ação intencional em alguma direção ou propósito". Nesse caso, conforme observam Kamii e Declark (1986, p. 171), "muitos adultos, inclusive professores, falham no conhecimento da importância dos jogos".

O jogo pode ser usado para ensinar um conceito novo, para revisar um tema ou como atividade de reforço. Para Kimura (2005, p. 136), “[...] ao utilizarmos o jogo como objeto, como ferramenta de ensino deve-se ter em mente a sua adequação ao conteúdo [...] e deve propiciar o engajamento do aluno no processo ensino-aprendizagem na construção de conceitos matemáticos". Assim, é importante o professor estar ciente do objetivo de cada jogo.

Para Grando e Marco (2007, p. 102):

[...] a utilização de jogos no ensino da Matemática, quando intencionalmente definidos, pode não apenas promover um contexto estimulador e desafiante para o movimento de formação do pensamento do ser humano, de sua capacidade de cooperação, mas também tornar-se um auxiliar didático na produção de conhecimentos matemáticos. Entendemos que o jogo é um facilitador da aprendizagem, pois mobiliza a dimensão lúdica para a resolução de problemas, disponibilizando ao aluno a aprendizagem, mesmo que a formalização do conceito seja a posteriori ao jogo.

De acordo com Lacanallo (2011, p. 109), o jogo auxilia na explicação de um conceito: "[...] quando conhecemos os jogos, em sua natureza histórica e social, o trabalho com o sistema de conceitos é possível e enriquece a aprendizagem dos escolares". Portanto, o jogo apresenta diversos aspectos motivadores para aprendizagem e é sempre recomendável conhecer a história, a linguagem, a cultura e as crenças do povo que o criou e saber explicar a relação entre o jogo proposto e o conceito novo apresentado.

Bôas (2007, p. 53) defende o uso de jogo, pois o fato de "[...] alguns perpetuarem-se através dos séculos, e de os homens continuarem inventando outro a cada dia, é um indicador de sua importância”. Para a autora, é jogando que o estudante questiona, demonstra suas angústias, constrói respostas pessoais, além de auxiliar seus colegas nos momentos de dúvidas, tornando-se uma atividade prazerosa e envolvente, geradora de interesse e discussões acaloradas.

No entanto, para que o jogo se torne um recurso importante relacionado com um conteúdo, ele deve ser bem planejado e demonstrar a sua funcionalidade:

\footnotetext{
O Jogo na Educação Matemática tem uma intencionalidade; ele deve estar carregado de conteúdo. É um conteúdo que não pode ser apreendido pela criança apenas ao manipular livremente objetos. É preciso jogar. E ao fazê-lo é que se constrói o objetivo a que se quer chegar. [...] O jogo tem um desenvolvimento próprio. Ele não pode ser a matemática transmitida de brincadeira. Deve ser a brincadeira que evolui até o conteúdo sistematizado. (MOURA apud BÔAS, 2007, p. 65)
}

Em seus estudos, Bôas (2007, p. 55) considera que “[...] não se trata de oferecer situações para que a criança enfrente com mais facilidade conteúdos escolares considerados ávidos pelo professor, mas sim de utilizar situações desafiadoras em que ele possa, [...] produzir novos conhecimentos". Já, para Silva e Scartazzini (2006, p. 26) “[...] deve-se levar em conta que o 
mesmo precisa ser capaz de despertar o interesse do aluno e integrá-lo na sua execução de modo satisfatório e desafiador, para que ele se empenhe ao máximo na sua solução".

É interessante que, após o final da aplicação de cada jogo, a tomada da consciência da própria ação se torne um item obrigatório e pode ser discutida pelo professor com seus estudantes. Desse modo, ocorre um momento propício para esclarecer inclusive os conceitos matemáticos intrínsecos ao jogo, ou seja, essa é uma oportunidade do professor conhecer e esclarecer as dúvidas ou dificuldades encontradas pelos estudantes. Os jogos podem ser repetidos com o objetivo de contribuir para a fixação ou revisão de conceitos.

Na concepção de Macedo, Petty e Passos (2005, p.17), as crianças jogam e "não se perdem em conversas paralelas permanecendo interessadas e envolvidas nas atividades [...] se não agirem assim, certamente seus colegas irão cobrar-lhes isso, sob pena de serem excluídas", ou seja, em se tratando de uma atividade lúdica, ninguém gosta de ser excluído de uma equipe.

O jogo é um momento lúdico que desperta interesse e muitos estudantes gostam desse momento por não temer o erro, ter a oportunidade de compartilhar suas dúvidas com seus pares e pelo simples prazer por jogar. Ressaltam Smole, Diniz e Milani (2007, p. 10): “[...] todo jogo por natureza desafia, encanta, traz movimento, barulho e certa alegria para o espaço no qual normalmente entram apenas o livro, o caderno e o lápis", mesmo que a intenção seja trabalhar conceitos matemáticos, o jogo ainda atrai os estudantes pela sua dimensão lúdica. Para Friedmann (1996, p. 56), é importante "[...] resgatar a atividade lúdica, sua espontaneidade e, junto com ela, sua importância no desenvolvimento integral das crianças", pois mesmo que o jogo seja visto por elas como uma brincadeira, ele se torna uma atividade séria quando se pretende saber quem vai ganhar o jogo.

Quando um professor pretende trabalhar com jogos, se organiza e planeja para que os estudantes tenham prazer em aprender. Kishimoto (2007, p. 84) considera que:

\footnotetext{
O professor vivencia a unicidade do significado de jogo e de material pedagógico, na elaboração da atividade de ensino, ao considerar nos planos afetivos e cognitivos, os objetivos, a capacidade do aluno, os elementos culturais e os instrumentos (materiais e psicológicos) capazes de colocar o pensamento da criança em ação.
}

Segundo Grando (2004, p. 8), "a necessidade do homem em desenvolver atividades lúdicas, ou seja, atividades cujo fim seja o prazer que a própria atividade pode oferecer, determina a criação de jogos e brincadeiras", e sua importância é determinada pelo professor. O jogo gera situações em que o estudante necessita se sentir seguro para conseguir coordenar seus conflitos, estabelecer uma ordem e expressar suas dúvidas em relação ao conteúdo ministrado.

Para Rizzo (1996, p. 40, grifo do autor): "O jogo motiva e por isso é um instrumento muito poderoso na estimulação da construção de esquemas de raciocínio" e ainda, segundo a autora, o jogo proporciona o desafio e "[...] mobiliza o indivíduo na busca de soluções ou de formas de adaptação a situações problemáticas e, gradativamente, o conduz ao esforço voluntário".

O jogo pode ser considerado um recurso que auxilia o professor para promover aulas mais dinâmicas, desafiadoras, mobilizando o estudante ao aprendizado mais prazeroso e que ocorre principalmente mediante a troca com outros. 


\section{O PAPEL DO PROFESSOR: ORGANIZADOR E OBSERVADOR DOS JOGOS}

Os estudos de Grando (2000) relatam que o professor deve intervir auxiliando na análise das partidas e identificando as jogadas equivocadas. Para tanto, é importante que o professor observe atentamente seus alunos jogando e sua atenção deve estar voltada para os questionamentos e para as observações dos estudantes. A intervenção do professor deve enfocar o aprendizado dos conceitos matemáticos. Para que o estudante se aproprie dos conceitos, o professor deve assumir o papel de organizador e observador, para que se cumpra o objetivo previamente estabelecido: o conhecimento do conteúdo matemático.

O jogo pode ser considerado, pelo professor, um instrumento facilitador de aprendizagem de estruturas matemáticas. Conforme Grando (2000, p. 28), a utilização de jogos em aulas de matemática serve como "suporte metodológico", sendo importante que alcance os objetivos estabelecidos pelo professor e seja desafiador para o estudante. As diferentes formas de apresentar o jogo contribuem e interferem nas possibilidades de seu uso. Para Teixeira (2008, p. 25), "[...] o professor deve refletir-se na organização do espaço, na seleção dos jogos e na interação com as crianças", sendo importante que organize e limite o uso de jogos para que as aulas não se tornem repetitivas e para que o jogo alcance seu valor pedagógico.

Em qualquer momento do jogo, o professor, como mediador, pode verificar se está acontecendo o cumprimento das regras e administrar eventuais conflitos. Teixeira (2008, p. 62) considera: "[...] cada aluno pode descobrir as qualidades dos demais, algumas vezes ocultas pela rotina [...]. É importante a ocasião para a percepção de que os demais são em geral diferentes dele próprio". Quando estão jogando em grupo, os estudantes refletem e trocam ideias sobre a sua jogada e a do adversário, e, na busca de uma melhor jogada, encontram soluções mais interessantes.

O importante no jogo não é apenas a sua característica lúdica, mas também o envolvimento e a mobilização decorrente do desejo de jogar. Segundo Rizzo (1996, p. 41): "O jogo em grupo é diferente, pois ele obriga a criança a descentralizar, a sair do seu próprio egocentrismo, a obriga a antecipar a ação do outro jogador e as suas próprias, como hipóteses, numa jogada mais complexa". Cabe ao professor organizar e acompanhar as ações dos estudantes durante as partidas, observando, controlando os procedimentos realizados, percebendo as maiores dificuldades de entendimento e quais estudantes não alcançaram o resultado esperado.

Lacanallo (2011) discute a importância da ação do professor, ajudando a vencer as dificuldades até que todos aprendam e realizem com independência os cálculos propostos no jogo. Para que esse momento ocorra de maneira prazerosa, o professor deve reconhecer as potencialidades do jogo, gostar e saber jogar, pois organizar atividades com jogos não é tarefa fácil porque gera indisciplina, agitação, briga entre ganhador e perdedor. Outros fatores interferem na decisão de usar jogos, como por exemplo, espaço físico, tempo suficiente para o entendimento do jogo, tempo e disponibilidade financeira para a confecção dos materiais. Para Lacanallo (2011, p. 196), "a ação lúdica e seus efeitos sobre a aprendizagem e o desenvolvimento não é natural e imediata" e o jogo, como recurso metodológico, deve ser explorado pelo professor em suas diferentes possibilidades, tais como, material utilizado para jogar e uso de regras.

Teixeira (2008) avalia que um jogo bem organizado e desafiador dificilmente deixará de ensinar alguma coisa. Antes de apresentá-lo aos estudantes, é fundamental o planejamento, o conhecimento do professor sobre as suas características e funcionalidades. Para Teixeira 
(2008, p. 25), "[...] esse planejamento requer do profissional atitude de disponibilidade para a atualização, abertura de espírito, empenho, responsabilidade e flexibilidade para mudanças", ou seja, é o que se espera de um profissional da educação diante de um mundo moderno e em constante transformação.

No papel de mediador, o professor deve sempre estar atento para auxiliar os estudantes na organização do conhecimento, exigindo reflexão das jogadas e incentivando-os na autonomia da aprendizagem. Nessa situação, o professor deixa de ser um detentor do saber e em conjunto com seus alunos os motiva para a pesquisa. Teixeira (2008, p. 63) considera que "[...] essa mediação acarreta possibilidades ao professor porque exige uma reflexão conjunta com os alunos que, por sua vez, passam a pensar, a buscar informações e a construir os elementos do conhecimento, capazes de conduzir a autonomia", ou seja, o professor exerce em sala de aula o papel de um técnico de um time ou juiz de uma partida que orienta e organiza em prol de objetivos previamente planejados.

O papel pedagógico do professor no uso de jogos é estimular o crescimento de seu aluno, avaliar seu potencial, guiá-lo e ajudá-lo compreender o processo que envolve um jogo. Contudo, antes de apresentar um jogo a um grupo, o professor precisa conhecê-lo, observando os procedimentos adequados e as dificuldades que o material produzido pode apresentar. O professor, segundo Bôas (2007, p. 55), deve "[...] ler suas regras, jogá-lo com outras pessoas para apropriar-se dele, analisá-lo com relação ao material, adequação para a faixa etária, o tempo que ele requer e as possíveis dificuldades", facilitando seu trabalho ao propor o jogo como atividade de aprendizagem.

Bianchini, Gerhard e Dullius (2010, p. 4) apontam alguns objetivos que o professor deve considerar: "Ao optar pelo jogo como estratégia de ensino seu desejo é propiciar a aprendizagem. O jogo, nesse contexto, deve cumprir o papel de auxiliar", e para que aconteça a aprendizagem do conceito matemático, a ação não deve ser isolada, professor e estudante devem agir em conjunto. Durante a realização de um jogo, o professor deve agir como observador e identificar se todos estão envolvidos e compreendendo as estratégias e as regras para que se cumpra o entendimento ou revisão do conteúdo proposto na atividade.

Considerando os estudos de Lacanallo (2011), três importantes aspectos são apontados para a apropriação de conceitos matemáticos num jogo: preparação para o jogo, a ação de jogar e suas estratégias e relações desenvolvidas ao longo da atividade. A autora aponta que o professor deve conhecer seus estudantes, e quais são suas organizações físicas e psíquicas antes de aplicar um jogo. O professor deve organizar as mesas e cadeiras para que estejam bem posicionadas e facilitando a visualização das peças pelos jogadores. O número de peças de um jogo, as cores dos baralhos e quem são os adversários também devem ser considerados em situações de jogo em sala de aula.

Teixeira (2008, p. 67) explica: “[...] o objetivo do professor no trabalho com jogos é valorizar o papel pedagógico do jogo, ou seja, desencadeamento de um trabalho de exploração e/ou aplicação de conceitos matemáticos". Ao refletir sua prática em sala de aula, o professor deve considerar que o jogo auxilia o estudante a construir seu próprio conhecimento. Teixeira (2008, p. 72) relata:

[...] o jogo está no centro do paradigma que destaca a aprendizagem ao invés do ensino, colocando parte do controle do processo de aprendizagem nas mãos do aprendiz. Daí pode auxiliar o professor a entender que a educação não é somente a transferência de conhecimento, mas um processo no qual o professor tem seu papel fun- 
damental, de mediação, na construção do conhecimento pelo aluno, como produto do seu próprio engajamento docente.

O tempo para execução do jogo deve ser considerado pelo professor a partir da organização do espaço, da apresentação das regras, das partidas realizadas como modelo e a execução propriamente dita. Portanto, recomenda-se repetir um jogo diversas vezes, para que o professor possa alcançar os objetivos que foram previamente planejados. Quando a atividade é repetida diversas vezes, o estudante tem a oportunidade de se apropriar melhor das estratégias do jogo e melhorar o seu raciocínio com relação ao conteúdo e as regras propostas. Para alcançar um objetivo, é necessário reflexão, discussão, o registro dos cálculos realizados e o esclarecimento das dúvidas que surgem durante o jogo. Smole, Diniz e Milani (2007, p. 17), defendem a repetição dos jogos em função das pesquisas que realizaram "[...] observando e investigando o uso de jogos diretamente junto aos alunos, nas escolas que tivemos a oportunidade de acompanhar".

É importante que, para o professor, a ação do jogo seja propícia ao desenvolvimento da imaginação dos estudantes, que criam diferentes formas de se expressar, com naturalidade, com atitudes diferentes do permitido em aulas tradicionais. É muito importante também, dentro das possibilidades de cada jogo, que seja mantido um diálogo entre os estudantes e professor, enriquecendo o aprendizado. Considerando a ação do professor, Grando (2000, p. 36-37) alerta:

\footnotetext{
Deve-se lembrar ainda que o professor não se isole do processo, mas que seja elemento integrante, ora como observador, juiz e organizador, ora como questionador, enriquecendo o jogo, mas evitando interferir "muito" no seu desenrolar. Portanto, como um elemento mediador entre os alunos e o conhecimento, via a ação no jogo.
}

O jogo é uma atividade dinâmica, desencadeada pelo prazer do próprio movimento. Para Raupp (2009, p. 40), “[...] se não houver o momento lúdico, provavelmente o jogo não despertará interesse e será visto como mais uma atividade, sem razão de ser”.

\section{CONSIDERAÇÕES FINAIS}

Jogos didáticos constituem um recurso pedagógico que pode ser utilizado no estudo da matemática, como atividade de fixação de um tema e também na revisão de conteúdos. Substituindo as tradicionais listas de exercícios e trazendo o lúdico para a sala de aula, os jogos promovem a sociabilidade e interação com colegas e professor, possibilitam a oportunidade de tomada de decisões e desenvolvimento da autonomia, contribuem para que cada estudante conheça seus limites e oportunizam o exercício do controle da ansiedade. Jogos podem estimular a prática do cálculo mental, mas também podem ser realizados com o auxílio de lápis e papel para a realização de cálculos. Erros cometidos durante a realização de jogos são mais facilmente superados do que aqueles cometidos em avaliações escritas. Vencer um jogo demanda seguimento de regras, concentração, respeito aos colegas, atitudes exigidas no convívio social. Cabe ao professor o papel de planejar a realização de jogos, observar atentamente a realização das jogadas, identificar crianças que demandam auxílio e atuar como juiz em desavenças que eventualmente ocorram. 
Com este artigo espera-se contribuir para a valorização da realização de jogos didáticos no estudo da matemática no ensino fundamental.

\section{REFERÊNCIAS}

ALVES, E. M. S. A ludicidade e o ensino de matemática. 4. Ed. Campinas-SP: Papirus, 2001.

BIANCHINI, G; GERHARDT, T; DULLIUS, M.M. Jogos no ensino de matemática "quais as possíveis contribuições do uso de jogos no processo de ensino e de aprendizagem da matemática?" Destaques Acadêmicos CETEC/UNIVATES, RS, ano 2, n. 4, 2010.

BÔAS, M. C. V. Construção da noção de número na educação infantil: jogos como recurso metodológico. São Paulo, 2007. 129p. Dissertação (Mestrado em Educação) - Faculdade de Educação, Universidade de São Paulo (USP).

BRASIL. Ministério da Educação. Secretaria de Educação Básica. Parâmetros Curriculares Nacionais: matemática. Brasília, 1998.

FRIEDMANN, A. Brincar: crescer e aprender - O resgate do jogo infantil. São Paulo: Moderna, 1996.

GRANDO, C. R. O jogo e suas possibilidades metodológicas no processo ensinoaprendizagem da matemática. Campinas, SP, 1995. 175p. Dissertação (Mestrado em Educação) - Faculdade de Educação, UNICAMP.

O conhecimento matemático e o uso de jogos em sala de aula. Campinas, 2000. 224 p. Tese (Doutorado em Educação) - Faculdade de Educação, Universidade Estadual de Campinas.

KAMII, C; DECLARK, G. Reinventando a aritmética: implicações da teoria de Piaget. São Paulo: Papirus, 1986.

KIMURA, C.F.K. O jogo como ferramenta no trabalho com números negativos: um estudo sob a perspectiva da epistemologia genética de Jean Piaget. São Paulo, 2005. 249 p. Tese (Doutorado em Educação) - Universidade Pontifícia Universidade Católica de São Paulo.

KISHIMOTO, T. M. Jogo, brinquedo, brincadeira e educação. 3. ed. São Paulo: Cortez, 1994. 
LACANALLO, L.F. O jogo no ensino da matemática: contribuições para o desenvolvimento do pensamento teórico. Maringá, PR, 2011. 218 p. (Mestrado em Educação) - Programa de Pós-Graduação em Educação, Universidade Estadual de Maringá.

LOPES, M.G. Jogos na educação: criar, fazer, jogar. 2 ed. rev. São Paulo, Cortez, 1999.

MACEDO, L. Ensaios Construtivistas. São Paulo: Casa do Psicólogo, 1994.

; PETTY, A.L.S.; PASSOS, N.C. Os jogos e o lúdico na aprendizagem escolar. Porto Alegre: Artmed. 2005.

RAUPP, A.D. Educação matemática: processos interativos em situações de jogo no ensino fundamental. Passo Fundo, RS, 2009. 137p. Dissertação (Mestrado em Educação) - Universidade de Passo Fundo.

RIZZO, G. Jogos Inteligentes: a construção do raciocínio na escola natural. Rio de Janeiro: Beltrand Brasil, 1996.

SILVA, É. D.; SCARTAZZINI, L. S. Jogos e desafios no ensino de Matemática: avaliação quantitativa em turmas de sexta série do ensino fundamental. Acta Scientiae: Revista do Centro de Ciências Naturais e Exatas - Universidade Luterana do Brasil - Canoas. n. 1. V. 8. P. 25-33, jan/jun 2006.

SMOLE, K.S.; DINIZ, M.I.; MILANI, E. Jogos de Matemática: de $6^{\circ}$ a $9^{\circ}$. (Cadernos do Mathema). Porto Alegre: Artmed, 2007.

STAREPRAVO, A.R. Mundo das ideias: jogando com a matemática, números e operações. Curitiba: Aymará, 2009.

TEIXEIRA, S.F.A. Uma reflexão sobre a ambiguidade do conceito de jogo na educação matemática. 2008. 102f. Dissertação (Mestrado em Educação) - Faculdade de Educação da Universidade de São Paulo. 